\title{
Global kundenorientiert
}

„Wir sind dort, wo unsere Kunden sind.“ Dieses Prinzip von MANN+HUMMEL reicht bis in die 1950er Jahre zurück. Mit Auslandsproduktionsstätten in Argentinien und Brasilien machte MANN+HUMMEL die ersten Schritte in Richtung Internationalisierung - und strebt bis heute nach globalem Wachstum. MANN+HUMMEL folgt seinen Kunden und produziert die Produkte dort, wo sie gebraucht werden. Mit dieser Strategie passt sich das Unternehmen konsequent an die globale Entwicklung an: Der Automobilmarkt befindet sich in einer langfristigen Wachstumsphase. Jährlich wächst die Nachfrage um etwa drei Prozent. Insbesondere in den asiatischen Ländern wie China und Indien sowie in Nordamerika und Russland ist der Wachstumsschub unaufhaltsam.
Dies gilt für den Erstausrüstungsbereich gleichermaßen wie für das Ersatzgeschäft. Das globale Marktvolumen in der Automobilzuliefererindustrie wird sich nach den Prognosen von Marktforschern von einer Billion Euro im Jahr 2013 auf bis zu zwei Billionen Euro im Jahr 2020 erhöhen.

MANN+HUMMEL möchte an diesem Wachstum teilhaben und setzt die Globalisierung von Entwicklung, Produktion und Vertrieb bereits seit den 1990er Jahren an erste Stelle. Der Kauf von branchenverwandten Unternehmen, allen vorweg die 2016 vollzogene Übernahme des weltweiten Filtrationsgeschäfts der Affinia-Group, ist dabei ebenso wichtig wie der eigenständige Aufbau von Tochtergesellschaften und die Gründung von Joint Ventures.
Eine solch weitgreifende Internationalisierungsstrategie muss sorgfältig vorbereitet werden. Personelle und finanzielle Veränderungen oder kulturelle Unterschiede sind Herausforderungen, denen sich global präsente Unternehmen stellen müssen. MANN+HUMMEL begegnet diesen Risiken selbstbewusst - und mit Erfolg: Im Unternehmen arbeiten zum heutigen Zeitpunkt mehr als 20.000 Mitarbeiter an über 60 Standorten. Im globalen Netzwerk ist und bleibt der Standort Deutschland Entwicklungsmotor für Innovationen, beispielsweise mit dem im Juli 2016 eröffneten Technologiezentrum am Hauptsitz Ludwigsburg oder mit der größten Filterfabrik der Welt im bayrischen Marklkofen.

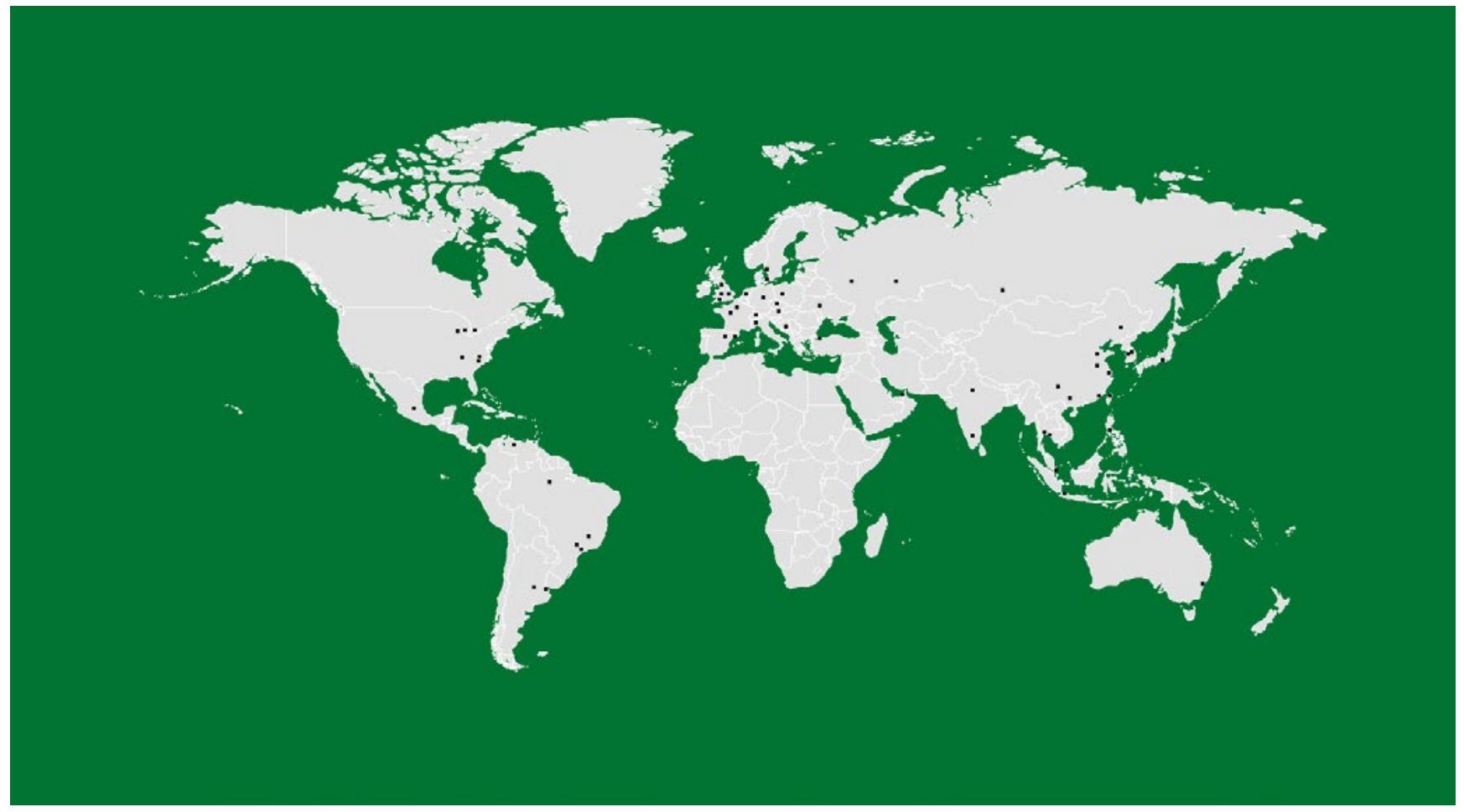

BILD 1 Standorte von MANN+HUMMEL sind über die ganze Welt verteilt (@ MANN+HUMMEL) 